\title{
Location and Diameter of the Posterior Superior Alveolar Artery among Iraqi Subjects Using Computed Tomography
}

\author{
Dr. Abdullah A. Ibrahim ${ }^{1}$, Prof Dr. Lamia H. Al Nakib ${ }^{2}$ \\ ${ }^{I}$ Master Student, Oral \& Maxillofacial Radiology, Department of Oral Diagnosis, College of Dentistry/ \\ University of Baghdad, Iraq. \\ ${ }^{2}$ Professor, Department of Oral Diagnosis, College of Dentistry/ University of Baghdad, Iraq.
}

\begin{abstract}
:
Background: Posterior superior alveolar artery (PSAA) is branch of the maxillary artery. It usually supplies the lateral wall of the sinus and overlying membrane. Evaluation and awareness of the anatomy of maxillary sinus before surgery is crucial to avoid surgical complications. The aim of this study is to examine the location and diameter using computerized tomography $(C T)$ scans.

Materials and Methods: This study included 180 Iraqi subjects ( 99 males and 81 females) with age more than 16 years old. CT scans for (right and left) Maxillary sinuses were done for each patient. The information obtained was assessed in a coronal multi planar reconstructions images (MPRs) in order to obtain the location and diameter of the PSAA.
\end{abstract}

Results: The PSAA was observed in $73.6 \%$ of all sinuses; $61.94 \%$ of arteries were intraosseous and the mean diameter was $(1.15 \pm 0.38) \mathrm{mm}$.

Conclusions: CT scan is valuable tool in evaluation and localization of the PSAA before maxillary sinus surgery.

Keywords: Computed tomography, Maxillary sinus, Maxillary artery, PSAA.

\section{Introduction}

The posterior superior alveolar artery (PSAA) and infraorbital artery (IOA) are the branches of the maxillary artery that supply the lateral sinus wall and overlying membrane. The blood supply of the maxillary sinus and Schneiderian membrane comes from the maxillary artery ${ }^{(1,2)}$. The branches of the maxillary artery should be taken into consideration during sinus augmentation because of the potential risk of bleeding during the procedure owing to damage to the vascular supply in the lateral wall ${ }^{(3)}$.

Performing maxillary sinus bone graft requires understanding the anatomy of maxillary sinus first. The pyramid shaped maxillary sinus is the largest of the paranasal sinuses ${ }^{(4)}$. Availability of sufficient bone volume is an absolute requirement for placing dental implants. In maxillary posterior regions, where bone atrophy and pneumatization of maxillary sinuses is a common sequela of tooth loss, placement of implants following a standard surgical protocol can be extremely challenging ${ }^{(5)}$. As in any other surgical intervention, a multitude of intra and postoperative complications may arise when performing sinus floor elevation procedures. One such complication is trauma to a blood vessel ${ }^{(6,7)}$.

Computerized tomography (CT) is a digital imaging technique that enables differentiation and quantification of soft and hard tissues. Arteries and other anatomical structures can be examined in CT images. CT can also be used to evaluate bone dimension, recognize specific anatomical landmarks, and to detect sinus pathologies ${ }^{(8)}$. Hence, this study was undertaken in order to show variations in the vascular morphology of the posterior superior alveolar artery in a sample of Iraqi subjects using CT scans.

\section{Materials And Methods}

The sample

The sample in this study composed of 180 Iraqi patients (99 males and 81 females) with an age not less than 16 years old. They attended the Radiology Department at Neuro Science Hospital in Baghdad / Iraq to take Spiral CT scan of the brain and paranasal sinuses from November 2015 till February 2016.

All participants were informed well about the aim and the method of the study and asked them if they agree to participate and they were free to withdrawal at any time they decide. A special consent form was to be signed by each one.

The patients were divided according to dental status into dentate and partially edentulous patients and then CT scans for (right and left) maxillary sinuses were taken for each patient using Siemens Somatom definition AS (Germany). The parameters of the acquisition were $1 \mathrm{~mm}$ thickness slice, $\mathrm{kV}=120, \mathrm{mAs}=370$ and exposure time was 20 seconds. The patients were positioned in supine on the CT examination table with the head on the head rest. 
The information obtained was the measurements parameters which were done using the calibration function of the syngo software program on syngo acquisition workplace in coronal multi planar reconstructions (MPRs), axial and coronal images were evaluated to reconfirm that the examined area contain artery canal.

These CT scan images were used to identify the PSAA in order to obtain the following parameters:

1. Locations of the artery were: intraosseous, below the membrane and on the outer cortex of the lateral sinus wall .(Figure 1).

2. Diameter of the artery. ${ }^{(10)}$.(Figure 2$)$.

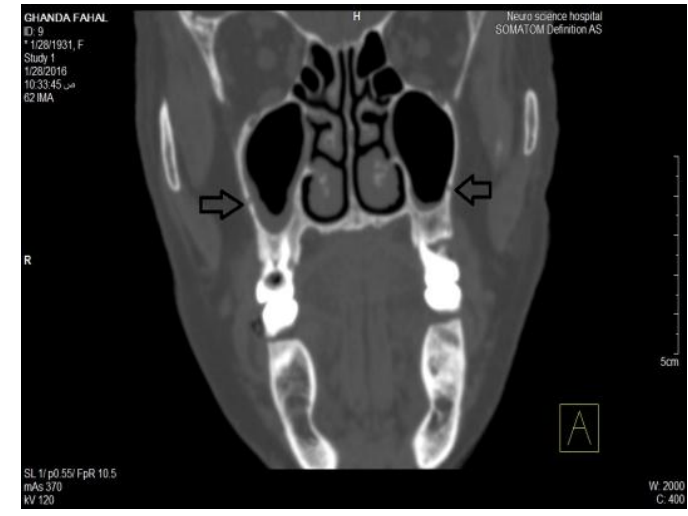

Figure 1: Coronal sections show the intraosseous artery (arrow).

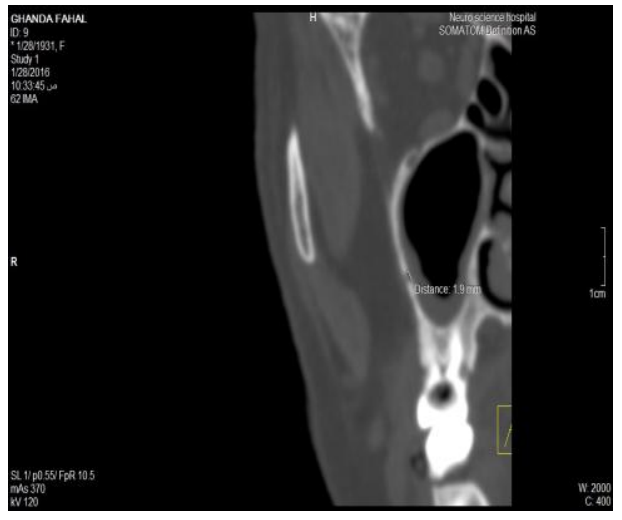

Figure 2: Coronal sections shows diameter of the PSAA.

\section{Statistical analyses}

were analyzed using SPSS (statistical package of social science) software version 19. In this study the following statistics were used:

1. Descriptive statistics: including means, standard deviations, frequency (No.), percentages, and statistical tables and figures.

2. Inferential statistics: including: Independent sample t-test: to verify the gender difference for the measured variables.

\section{Location of the PSAA}

\section{Results}

The position of the PSAA is subdivided in three categories according to its location on the sinus wall as follows:

1. Intraosseous.

2. Below the schneiderian membrane.

3. On the outer cortex of the lateral sinus wall.

In the present study for the total sample it was mostly intraosseous $(61.94 \%),(10 \%)$ was below the schneiderian membrane and only $(1.67 \%)$ was detected on the outer cortex of the lateral sinus wall and was absent radio graphically in $26.36 \%$ of the total sample.

The position of the PSAA was analyzed in relation to age, genders and according to the results of the present study there is a statistical significant correlation between the position of the PSAA in relation to age, gender (Table 1)(figure 3).

\begin{tabular}{|c|c|c|c|c|c|c|c|}
\hline \multirow{2}{*}{\multicolumn{2}{|c|}{ Genders }} & \multicolumn{6}{|c|}{ Position of PSAA } \\
\hline & & Absent & Intraosseous & $\begin{array}{l}\text { Below the } \\
\text { membrane }\end{array}$ & $\begin{array}{l}\text { on the outer } \\
\text { cortex of } \\
\text { the lateral } \\
\text { sinus wall }\end{array}$ & Total & p-value \\
\hline \multirow{2}{*}{ Female } & $\mathrm{N}$ & 60 & 85 & 14 & 3 & 162 & \multirow{6}{*}{$\begin{array}{l}0.001 \\
\text { (HS) }\end{array}$} \\
\hline & $\%$ & 37.04 & 52.47 & 8.64 & 1.85 & 100 & \\
\hline \multirow{2}{*}{ Male } & $\mathrm{N}$ & 35 & 138 & 22 & 3 & 198 & \\
\hline & $\%$ & 17.68 & 69.70 & 11.11 & 1.52 & 100 & \\
\hline \multirow{2}{*}{ Total } & $\mathrm{N}$ & 95 & 223 & 36 & 6 & 360 & \\
\hline & $\%$ & 26.39 & 61.94 & 10 & 1.67 & 100 & \\
\hline
\end{tabular}




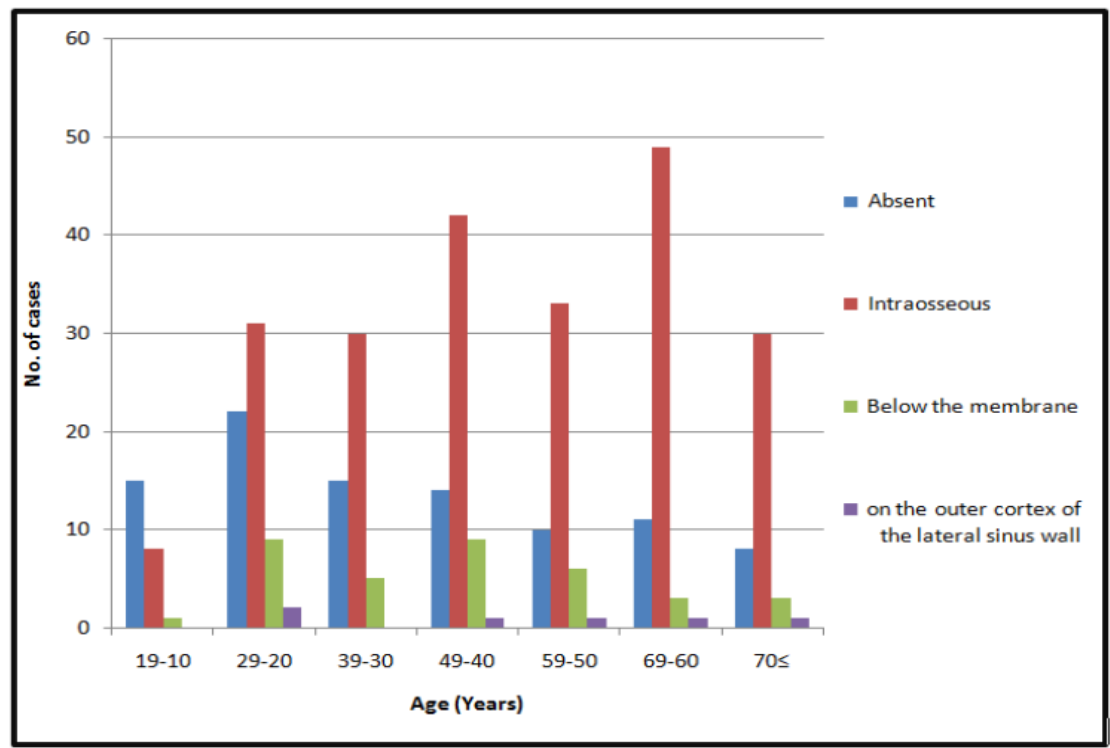

Figure 3 : PSAA position in relation to age.

\section{Diameter of the PSAA}

The mean diameter of the artery was $1.15 \pm 0.38 \mathrm{~mm}$ for the total sample in which it was $1.04 \pm 0.31$ $\mathrm{mm}$ in females and $1.21 \pm 0.40$ in males. Statistically there is a high significant with genders and the diameter as the P-value $=0.000$. (Table 2)

The diameter was classified within the range of less than $1 \mathrm{~mm}$ that seen in $33.96 \%$ and from $1-2 \mathrm{~mm}$ that seen in $62.26 \%$ and more than $2 \mathrm{~mm}$ that seen in $3.77 \%$ of cases. (Figure 4 ).

Table 2. Diameter in relation to gender

\begin{tabular}{|c|c|c|c|c|c|}
\hline \multirow{2}{*}{ Genders } & \multicolumn{3}{|c|}{ Descriptive statistics } & \multicolumn{2}{c|}{$\begin{array}{c}\text { Genders difference } \\
\text { (d.f.=263) }\end{array}$} \\
\cline { 2 - 4 } & $\mathrm{N}$ & Mean & S.D. & t-test & p-value \\
\hline Females & 102 & 1.04 & 0.31 & & -3.744 \\
\hline Males & 163 & 1.21 & 0.40 & $\begin{array}{c}\mathbf{0 . 0 0 0} \\
\text { (HS) }\end{array}$ \\
\hline
\end{tabular}

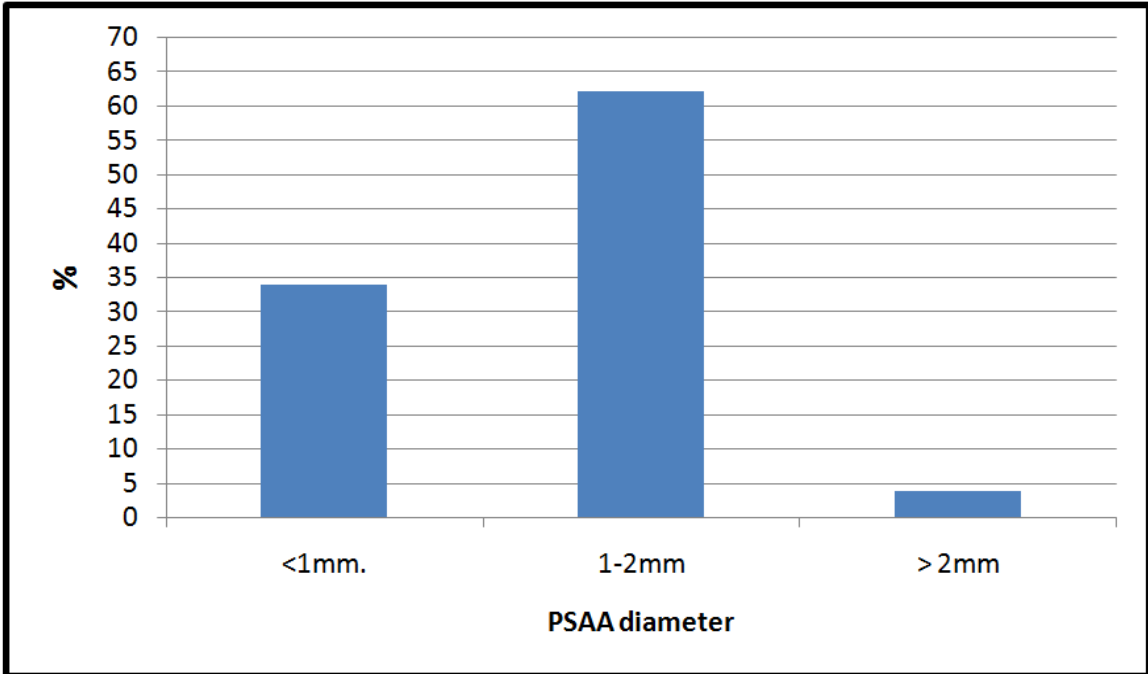

Figure 4. Classification of the PSAA diameter .

\section{Discussion}


The importance of considering the vascular system of the maxillary sinus when employing sinus surgery, particularly lateral approach sinus floor augmentation relates to potential intraoperative complications $^{(1,2,11)}$.

Sinus augmentation is a method with high predictability for placing successful dental implants into atrophic posterior maxilla ${ }^{(12,13)}$. Blood vessels distribution in this area changes when the alveolar bone is severely atrophied because of increased age and loss of dentition. Moreover, the number and diameter of the blood vessels may decrease in elderly edentulous patients ${ }^{(14)}$, so knowledge of the anatomic structure of the area is important for this procedure.

\section{Position of the PSAA}

The PSAA was visualized in(73.6\%) of all sinuses and the position of the artery was mostly intraosseous in $(61.94 \%),(10 \%)$ was below the schneiderian membrane and only $(1.67 \%)$ was detected on the outer cortex of the lateral sinus wall. these results is similar to that reported by Guncu et al. ${ }^{(8)}$

\section{Diameter of the artery}

According to our current results, the mean artery diameter was $1.15 \pm 0.38 \mathrm{~mm}$. However, Kim et al. ${ }^{(14)}$ ,Guncu et al. ${ }^{(8)}$ reported larger diameters of $1.52 \pm 0.47 \mathrm{~mm}, 1.3 \pm 0.5 \mathrm{~mm}$, respectively and Ella et al. ${ }^{(3)}$ in 2008 and Fontana et al. ${ }^{(15)}$ found that the mean diameter of the vessels was $1.2 \mathrm{~mm}$ which is the nearest to our results.

In the sample of the present study, the artery diameter was $<1 \mathrm{~mm}$ in $33.96 \%$ of the total sample. Guncu et al. ${ }^{(8)}$ reported only $36.1 \%$ of arteries were $<1 \mathrm{~mm}$, Mardinger et al. ${ }^{(10)}$ reported $26 \%$ and $\mathrm{Kim}^{\text {et }}$ al. $^{(14)}$ detected $13.90 \%$ of vessels with diameters $<1 \mathrm{~mm}$.

The observation is in agreement with Guncu et al. ${ }^{(8)}$, Mardinger et al. ${ }^{(10)}$ but disagreed with Kim et al. ${ }^{(14)}$ because in his study the age of the patients examined was limited to 45-65 years while in our study it was above 16 years old.

The mean diameter of arteries was higher in males $(1.21 \pm 0.4 \mathrm{~mm})$ than females $(1.04 \pm 0.31 \mathrm{~mm})$ in this study which is similar to that reported by Guncu et al. ${ }^{(8)}$ and Kim et al. ${ }^{(14)}$ however Mardinger et al. ${ }^{(10)}$ found no difference between male and female regarding the diameter of the artery.

Mardinger et al. ${ }^{(10)}$ stated that the canal diameter was directly related to the age of the patient. Older patients have wider canal diameters. No correlation was found with gender, presence of teeth and sinus site (right or left).we contradicts this statement of Mardinger et al. ${ }^{(10)}$ regarding the effect of age and gender on the canal diameter.

According to this study results, the diameter of the PSAA was significantly larger in male than in female and only larger canals can be detected on CT images, therefore the gender may affect the detection of the PSAA on CT images.

\section{Conclusion}

1. The location of the PSAA was mostly intraosseous in(61.94\%)of diagnosed canals.

2. The diameter of the PSAA was $1.15 \pm 0.38 \mathrm{~mm}$. it was less than $1 \mathrm{~mm}$ in $33.96 \%$ and was $62.26 \%$ in range from $1-2 \mathrm{~mm}$ and it was $3.77 \%$ more than $2 \mathrm{~mm}$, it was larger in males.

\section{References}

[1]. Solar P, Geyerhofer U, Traxler H, Windisch A, Ulm C, Watzek G. Blood supply to the maxillary sinus relevant to sinus floor elevation procedures. Clin Oral Implants Res 1999; 10: 34-44.

[2]. Traxler H, Windisch A, Geyerhofer U, Surd R, Solar P, Firbas W. Arterial blood supply of the maxillary sinus. Clin Anat 1999; 12, 417-21.

[3]. Ella B, Sedarat C, Noble Rda C, Normand E, Lauverjat Y, Siberchicot F, Caix P, Zwetyenga N.Vascular connections of the lateral wall of the sinus:surgical effect in sinus augmentation. Int J Oral Maxillofac Implants 2008; 23, 1047-52.

[4]. Park WH, Choi SY, Kim CS. Study on the position of the posterior superior alveolar artery in relation to the performance of the maxillary sinus bone graft procedure in a Korean population. J Korean Assoc Oral Maxillofac Surg 2012; 38 , 71-77.

[5]. Anamali S, Avila-Ortiz G, Elangovan S, Qian F, Ruprecht A, Finkelstein M, et al. Prevalence of the posterior superior alveolar canal in cone beam computed tomography scans. Clin Oral Implants Res. 2015;26(1):e8-12.

[6]. Flanagan D.Arterial supply of maxillary sinus and potential for bleeding complication during lateral approach sinus elevation. Implant Dent 2005; 14, 336-8.

[7]. Testori T, Rosano G, Taschieri S, Del Fabbro M. Ligation of an unusually large vessel during maxillary sinus floor augmentation. A case report. Eur J Oral Implantol 2010;3, 255-8.

[8]. Guncu GN, Yildirim YD, Wang, HL, Tozum TF. Location of posterior superior alveolar artery and evaluation of maxillary sinus anatomy with computerized tomography: a clinical study. Clin Oral Implants Res 2011; 22, 1164-7.

[9]. Elian N, Wallace S, Cho SC, Jalbout ZN, Froum S.Distribution of the maxillary artery as it relates to sinus floor augmentation. Int J Oral Maxillofac Implants 2005; 20, 784-7.

[10]. Mardinger O, Abba M, Hirshberg A, Schwartz-Arad D.Prevalence, diameter and course of the maxillary intraosseous vascular canal with relation to sinus augmentation procedure: a radiographic study. Int J Oral Maxillofac Surg 2007; 36, 735-8.

[11]. Rosano G, Taschieri S, Gaudy JF, Weinstein T, Del Fabbro M. Maxillary sinus vascular anatomy and its relation to sinus lift surgery. Clin Oral Implants Res 2011; 22, 711-5. 
Location And Diameter Of The Posterior Superior Alveolar Artery Among Iraqi Subjects Using...

[12]. Wallace SS, Froum SJ. Effect of maxillary sinus augmentation on the survival of endosseous dental implants. A systematic review. Ann Periodontol 2003; 8, 328-43.

[13]. Pjetursson BE, Tan WC, Zwahlen M, Lang NP. A systematic review of the success of sinus floor elevation and survival of implants inserted in combination with sinus floor elevation. J Clin Periodontol 2008; 35, 216-40.

[14]. Kim JH, Ryu JS, Kim KD, Hwang SH, Moon HS. A radiographic study of the posterior superior alveolar artery. Implant Dent 2001; 20, 306-310.

[15]. Fontana III, John Battista; Reynolds, Mark A.Maxillary Sinus Morphology: A Radiographic Retrospective Evaluation of the Posterior Superior Alveolar Artery in Caucasian and African-American Subjects. (Master's thesis, University of Maryland, Baltimore. Biomedical Sciences-Dental School), 2012. 